\title{
How Does Gulture Matter? The Xin (Heart-Mind)-based Social Competence of Chinese Executives
}

\section{Hongguo Wei, ${ }^{1}$ Diana Bilimoria, ${ }^{2}$ and Shaobing $\mathrm{Li}^{3}$ \\ ${ }^{1}$ University of Central Oklahoma, USA, ${ }^{2}$ Case Western Reserve University, USA, and ${ }^{3}$ Miami University, USA}

\begin{abstract}
In this study we explore the emotional and cognitive dimensions of Chinese business leaders' social competence. We argue for a culturally inclusive conceptualization of leader social competence and its internal structure, which takes into account Chinese indigenous features. Data were collected by critical incident interviews from 42 top executives of small- and medium-sized private enterprises in China. A total of 302 competency episodes were included in the current study. Grounded theory was used for data analysis. The following xin (heart-mind)-based social competencies were referenced in episodes of effective Chinese competency-relevant social interactions: guanxi building and maintenance, empathy, inspiration with wisdom, empowerment and developing others, resilience, and appreciation of problem solving. Each of these competencies includes an emotional and a cognitive element and embodies dynamic interplay between the emotional and cognitive dimensions of social competence. Xin-based social competencies impact effective interactions in relational contexts that implicate the individual self, the organizational self, and their interactions. The theoretical contributions and practical implications of the findings are discussed.
\end{abstract}

KEYWORDS cognition and emotion, cognitive system of yin-yang balancing, leadership effectiveness, self and other, social competence, top executives

\section{INTRODUGTION}

Social competence is defined as effectiveness and appropriateness in social situations and is demonstrated through a system of behaviors contextualized between oneself and others (Rose-Krasnor, 1997; Waters \& Sroufe, 1983). Previous research on leaders' social competence has analyzed the internal structure of social competence based on emotional and cognitive dimensions mainly in the Western culture context (Goleman, Boyatzis, \& MacKee, 2002; Rose-Krasnor, 1997; Yeates \& Selman, 1989). Yet little research has been done to examine the applicability 
of social competence in leadership effectiveness and its internal structure in a non-Western culture such as the Chinese culture. Since social competence is context dependent, the examination of this concept for leadership effectiveness in a non-Western context needs to explore how the social culture and organizational context (e.g., job characteristics and job role requirements) impact the demonstration and application of leaders' social competence.

Extant assumptions of social competence in Western literature reflect two aspects: (1) emotional and cognitive dimensions are correlated (Goleman et al., 2002; Mayer, Salovey, \& Caruso, 2004) albeit little work explores the mechanisms of how they are correlated, and (2) the self is an independent entity (e.g., Bellah, Madsen, Swidler, \& Tipton, 2007), and thus the self and other contextual domains are orthogonal and satisfy different needs (e.g., individual needs of autonomy versus needs of communion) (Bakan, 1966). Upon a closer examination of these assumptions in indigenous Chinese literature with traditional and recent viewpoints included, we find other distinctive assumptions as follows: (1) in indigenous Chinese research, the emotional and cognitive dimensions are usually seen as two paradoxical elements of a social relational construct (e.g., Chua, Morris, \& Ingram, 2009; Li, 2007b). They partially conflict and partially complement each other; and (2) the self is a social self as reflected in the concept of ren or benevolence (Chan, 1955), and thus the realization of the self is interdependent on social relations with others in the process of social interaction (e.g., Chuang, Hsu, Wang, \& Judge, 2015; Hwang, 2011; Tu, 2012). These differences in the underlying assumptions of social competence motivate our examination of leaders' social competence in the Chinese culture.

The present study investigates the following question - what are the assumptions, internal structure, and application of social competence to leadership effectiveness in the context of the Chinese culture? Specifically, we are interested in exploring the dimensions (emotional and cognitive) of the social competence of leaders within self and other domains in an indigenous Chinese culture. To answer this question, we adopted a grounded theory approach to inductively examine specific competencies distinguishing leadership effectiveness and then developed a theoretical framework in terms of the internal structure of social competence and how it applies in Chinese culture. We collected data from top executives in small- and medium-sized private enterprises (SMPEs) in China using criterion (or purposive) and snowball sampling and critical incident interview techniques.

The contributions of this study are threefold. First, at the theoretical level, we extend the research on social competence by examining its underlying assumptions, internal structure, and applicability in a non-Western culture, here, a Confucian culture. Second, we build a theoretical framework with a grounded theory approach to examine the internal relationships of specific competencies and how they impact leadership effectiveness. Third, at the practical level, our findings inform leadership education and development through a culturally relevant and methodologically rigorous social competence model. 
In the rest of the article, we first conduct a systematic review of the literature to define the main concepts and identify the assumptions of social competence under Western and Chinese culture, and thus propose the necessity of an inductive study in the context of the Chinese culture. We then explain the sampling strategy, data collection, and procedures of data analysis employed. The findings are presented next in the results section, followed by the theoretical and practical implications of the findings.

\section{THEORETIGAL BAGKGROUND}

\section{A Behavioral Approach to Social Competence}

Competence was primarily proposed to predict job performance by differentiating effective and less effective performers (McClelland, 1973). Scholars have employed several different perspectives to understand competence: 1) task or relationship related behaviors (Goleman et al., 2002; Rose-Krasnor, 1997), 2) overarching characteristics (i.e., ability, skills, and knowledge) (Hartle, 1995; Saarni, 1999), and 3) strategy effectiveness (Prahalad \& Hamel, 1990). The first perspective emphasizes behaviors predicting effectiveness (e.g., success, sustainability) in the workplace. The second perspective views competence as a mixed composite of individual abilities, skills, and static knowledge. The third perspective sees strategies as the core competence in organizational competition and development. Compared to the other two perspectives, the first perspective is the most suitable to understand social competence because of the following reasons: First, social competence mainly refers to effectiveness in interaction through organized behaviors that meet the developmental needs of both the short and long term (Rose-Krasnor, 1997; Yeates \& Selman, 1989). Second, scholars criticize that the second perspective is problematic and unrealistic, because it assumes that each great leader has a set of all the useful competencies and these mixed competencies are independent of each other and of the context (e.g., Hollenbeck, McCall, \& Silzer, 2006). Further, the third perspective is usually used at the macro organizational level and thus inappropriate to describe individual leader behaviors. In the field of leadership research, social competence has been shown to have a significant impact on leadership effectiveness (Goleman et al., 2002; Hollenbeck et al., 2006).

\section{Western Concepts and Assumptions of Social Competence}

With a careful examination of earlier and extant social competence research, we find that most researchers consider that social competence includes both the emotional and cognitive dimensions, and that both the self and others are important contexts in the social interaction process. We elaborate on each point below. 
The emotional and cognitive dimensions of social competence. In recent years scholars have begun to integrate emotion and cognition, two seemingly distinct concepts, to explain different aspects of social competence, developing relevant concepts such as 'emotional intelligence' (Mayer et al., 2004), 'emotional competence' (Goleman et al., 2002; Saarni, 1999), and 'affective social competence' (Halberstadt, Denham, \& Dunsmore, 2001). These concepts confirm the emotional aspect of social competence, that is, integrating emotions and affect into the intra- and inter-personal interaction. In addition, some scholars view social competence as social information processing (Crick \& Dodge, 1994), emphasizing the cognitive aspects of social competence. For instance, Baron and Markman (2003) used four aspects of social competence to explain entrepreneur success including social perception, impression management, social adaptability, and expressiveness. Two of these aspects (impression management and expressiveness) epitomize emotional social competencies, including elements such as the efficacious expression of one's own affect and emotions, successful interpretation and response to others' emotions and feelings, appropriate management of one's own affect, and vicarious communication in leadership (Goleman et al., 2002; Halberstadt et al., 2001). Two other aspects (social perception and social adaptability) epitomize cognitive social competencies, including accuracy in perceiving others' situations and thoughts, making decisions, managing and communicating based on rational thoughts, and adjusting oneself in accordance with situational changes (Halberstadt et al, 2001; Rose-Krasnor, 1997). Since social competence emphasizes organizing in social interaction, it is thus assumed to include both emotional and cognitive elements (Boyatzis, 2009; LaFreniere \& Dumas, 1996; Rose-Krasnor, 1997).

Yet little research has examined the relationship between the emotional and cognitive dimensions of social competence, especially the mechanisms of how they are related. Research on a similar social interaction concept, trust, may shed some light on our argument. Scholars point out that trust involves both the affective and cognitive aspects, and these two aspects are highly correlated to represent the same concept (Chua et al., 2009; Li, 2007b, 2008; McAllister, 1995). However, cognitionbased trust and affect-based trust generate different impacts on deception in Chinese and American contexts (Zhang, Liu, \& Liu, 2015). Specifically, affectbased trust is positively related to the approval of informational deception, yet it turns out that cognition-based trust reduces the approval of negative emotional and informational deception. Thus it is important to differentiate these two aspects of trust. Analogically, we argue that the emotional and cognitive dimensions of social competence are correlated but still need to be differentiated. Since it is yet unknown as to how these two dimensions are related and differentiated, we focus on this issue in the present study from a unique Chinese perspective.

Self and other as contexts of social competence. Social competence reflects the organizing behaviors between oneself and the other in interpersonal interaction, thus self and other serve as the context for competency behavior (Rose-Krasnor, 1997). As 
such, social competence as organizing behaviors in this process reflects both self and other domains. According to Rose-Krasnor (1997), the self-domain includes 'success in achieving one's own goals and feelings of efficacy in social interaction' and thus it indicates effectiveness from one's own perspectives; the other domain includes 'healthy relationships with peers and adults, achieving an appropriate place in social groups, and fulfilling society's expectations for responsible social behavior' and thus it reflects the needs, interests, and perspectives of connecting to others (122). It seems that the self and other domains aim accomplishing different goals or satisfying different needs, that is, a need for personal autonomy versus a need for personal connection or belonging (see Bakan, 1966). This statement aligns with the cultural assumption of individualism in Western culture (see Bellah et al., 2007). Thus, differentiating competence along the self and other domains has its cultural foundation in Western culture. However, in Confucian culture, the self is claimed to be the social self, that is, in relation to others (Chuang et al., 2015; Hwang, 2011). The fulfillment of oneself in a specific context is nurtured in and then facilitates social relation with others (Chuang et al., 2015). Thus, the differentiation of social competence into self and other domains in the Chinese culture may be problematic.

\section{An Exploration of Social Competence in the Ghinese Gultural Context}

Chinese organizations and management thoughts are considered a cultural product because of the long-term significant impact of Confucian values (Pan, Rowney, \& Peterson, 2012; Peng, Lu, Shenkar, \& Wang, 2001). A cross-cultural study examining data collected from Mainland China, Hong Kong, Taiwan, and Singapore found that 'Confucian dynamism' had a correlation of 0.75 with the economic growth from 1965 to 1984 (Connection, 1987). The study of social competence and executive leaders' effectiveness in Chinese cultural context is important and timely. First, as social competence is a context-dependent concept, the contextualization of this concept in Chinese culture enriches the meaning of social competence and the clarity of its internal structure. Social competence and the relationship of its different dimensions demonstrated by executive leaders in Western cultures may differ from those demonstrated in China. In addition, based on situational leadership (Hersey \& Blanchard, 1969), leadership effectiveness results from an integrative effect of interpersonal relationships (impacted by social competence) and macro and micro situations such as task characteristics and social context (Boyatzis, 2009; Hollenbeck et al., 2006). Below we provide conceptual theorizing and explanation based on indigenous Chinese philosophical thoughts.

The paradoxical nature of emotion and cognition as a duality in Chinese culture. As noted above, the emotional and cognitive dimensions of social competence are expected to be correlated in Western culture but there is little evidence in terms of what the overlaps are and how they are correlated. Recent research provides strong 
evidence of the usefulness of the Chinese cognitive system of yin-yang balancing to understand and interpret organizational phenomenon. For instance, Jing and Van de Ven (2014) developed a Chinese indigenous organizational change model based on the yin-yang philosophy. Zhang, Waldman, Han, and Li (2015) expounded paradoxical leader behaviors based on the yin-yang theory to explain how leaders handle the contradictory demands. We hence propose the appropriateness of using the Chinese cognitive system of yin-yang balancing to address the relationship between emotion and cognition in understanding social competence. As a frame of thinking, yin-yang balance has three core characteristics in explaining organizational phenomenon: holism, dynamism, and duality (Li, 2012). Existence is composed of the yin and yang duality, which contradict and complement each other in organizing a holistic entity (Zhang et al., 2015). The cognitive system of yin-yang balancing does not treat contradictions as problems but the core components of the existence, thus it pursues a balance of 'mutual negation and mutual affirmation between two opposites as a duality' (Li, 2012: 866). The cognitive thinking of yin-yang balancing epitomizes the paradoxical nature of emotion and cognition as a duality. In addition, following the cognitive system of yin-yang balancing, human existence embodied in forms of expressions and thoughts is not static but dynamic and transformative (Chen, 2008). In this regard, emotional and cognitive interaction is dynamic and cyclical rather than static (Ji, 2008). The dynamic and cyclical interaction between emotional and cognitive aspects of social competence reflects the social constitutional processes of social competencies. Thus from a cognitive system of yin-yang balancing, theoretically the two dimensions (i.e., emotional and cognitive) of social competence in Chinese culture partially contradict and partially complement each other, and their dynamic cyclical interaction comprises holistic social competence.

Based on this thinking of yin-yang balancing, we use the concept of xin, translated as heart-mind, to represent the paradoxical interaction between the emotional and cognitive aspects of social competence. First, the Confucian xin is a mixed construct including an inseparable heart (emotion) and mind (cognition) element (Mencius \& Lau, 1995). Xin adopts a holistic perspective to mind (cognition), body (physical state), and heart (emotion) to explain personal and interpersonal cultivation in social life (Wei \& Li, 2011). It thus is considered as the driving power of social learning and competence development. Second, integrating the thinking of yin-yang balancing to explain social existence, the mind (cognition) and heart (emotion) aspects are paradoxical in forming a holistic entity, thus they partially conflict and partially complement each other in shaping the existence of xin. As such, in Chinese culture a mixed emotional and cognitive concept built on $\mathrm{xin}$ is one approach to explain the connections and differentiation of the two dimensions of social competence. We term the mixed emotional and cognitive concept as 'mixed social competencies', which refers to the yin-yang balancing of emotion and cognition in social interaction. Further, social competence based on xin is accomplished through a cultivation system emphasizing the importance of 
family, kinship, fraternity, and social practice. This cultivation system promotes the dynamic and cyclical interaction of the cognitive and emotional aspects of social competence by assuming genuine emotional expression and human virtues in interpersonal interaction (Wei \& Li, 2011). For instance, Mencius encourages the implementation of benevolence, righteousness, propriety, and wisdom that are all rooted in xin (heart-mind) (Mencius \& Lau, 1995). We thus use the concept xin (mind-heart) to represent the holistic entity supporting the emotional and cognitive components of social competence.

The self and other domains in Confucian culture. Previous research suggests that the Confucian culture of ren, translated as benevolence, signifies that people tend to build harmonious relationships with others (Chuang et al., 2015). This is because the self in a collectivist culture tends to adjust to others' interests to guarantee a harmonious self-other relationship (Chuang et al., 2015; Tu, 1995). In this sense, the self in Confucian culture can be understood as the social or relational self (Hoe, 1998; Markus \& Kitayama, 1991). This viewpoint is in alignment with the collective or organizational self-illustrated in self-identity theory (Johnson, Selenta, \& Lord, 2006; Sparks \& Shepherd, 1992). Thus, it is possible that the individual accomplishment of a leader is fertilized in specific social interaction with others and even with an intent to attain organizational job role expectations (Chuang et al., 2015). Hence it is difficult to differentiate the leader's self and others' (e.g., organizational) goals and interests. With this in consideration, it is a challenge to differentiate social competence into the separated self and other domains; instead, the two domains may be embedded into each other and form pairs of contextual varieties between oneself and others. For instance, in Confucian culture the self-cultivation, that is, self-learning and development towards becoming a more fulfilled person, not only aids but also is contextualized in self-other interaction (Chuang et al., 2015). Recent indigenous research has provided evidence to support this viewpoint. For instance, Xiao and Tsui (2007) discovered that the structural holes theory of social capital developed in Western culture cannot be replicated in China because the structural holes would bring detrimental effects to the highly collective, clanlike, and high-commitment culture. This study found that 'integrators' who own large and dense ego-centered networks themselves and hold collective interests, bring unconnected people together in order to bridge the structural holes of others' interpersonal relationships, and they ultimately have greater career success than 'brokers' who benefit from other people's lack of connection (Xiao \& Tsui, 2007). Thus, we argue that the Confucian thoughts of the social self provides further evidence of not differentiating social competence into separated self and other domains but pairs of embedded contextual composition in Chinese culture.

To explore the dimensions (emotional and cognitive) and domains (self and other) of the social competence of executive leadership in a Confucian culture and how they are related, we conducted a qualitative study following a grounded theory approach (Corbin \& Strauss, 2008) as described below. A qualitative study 
enables us to employ an inductive approach to examine the different dimensions and domains of social competence in an indigenous Chinese culture. This increases the accuracy, originality and innovation in theory building of social construction processes (Gioia, Corley, \& Hamilton, 2013).

\section{METHOD}

\section{Participants}

We study top executive leaders (i.e., chief executive officer or deputy executive officer) from small- and medium-sized private enterprises (SMPEs) in China because their work requires the expression of social competence and they are typically in various social interactions to seek resources for company development (Xin \& Pearce, 1996). In addition, SMPEs are considered the products of the indigenous culture and society (Tan, 1996; Wank, 1996), which are stated as an important contributor to the Chinese economy (Khanna, 2007). We used criterion or purposive sampling strategy in the initial stage and snowball sampling strategy in the later stage of data collection (Patton, 1990). We chose participants who had at least a two-year tenure in their current position to maximize the quality of the descriptions of their stories. Participants were nominated by professional consultants, network nobles (i.e., people with well-established networks in a local city), professors, other participants, or by their reputation in a certain industry. Getting participants through various personal contacts not only aids in increasing the diversity of data but also it has been proved to be a valid approach to collect high quality data in the Confucian culture because participants are less likely to share authentically with a stranger interviewer (Chuang et al., 2015; Tsang, 1998). In the end we interviewed 42 participants (i.e., chief executive officers or deputy executive officers) from four cities in northern China. The final sample consisted of 4 females and 38 males. Among the valid cases, participants' tenure in their current job positions ranged from 2 to 20 years. The participants were from a diverse range of industries such as information technology, construction, consulting, property management, bank, media, etc., and the size of their respective enterprises ranged from 30 to 300 employees.

\section{Data Collection}

Following the requirements of the Critical Incident Interview (CII) methodology (Flanagan, 1954; McClelland, 1976), we pre-tested and revised a semi-structured interview protocol in Chinese before it was used with the executives to collect events with complete stories and rich content. The final interview questions centered around three broad categories: participants' current job roles and responsibilities, collection of two or three effective and two or three less effective (or ineffective) events in their leadership, and a reflection of other competencies they deemed as important. CII has been proven to be a reliable and valid method for obtaining 
descriptions of work-related behavior (Motowidlo et al., 1992). On-site interviews were conducted in Chinese and generally lasted from 60 to 90 minutes. The main questions used in the interviews included:

'What led up to the situation?', 'Who said or did what to whom?', 'What did you say or do next?', 'What were you thinking and feeling?', and 'What was the outcome or result of the event?' Questions were adjusted in the process of data collection based on responses from interviewees, particularly to adjust the questions to the Chinese cultural context and make them more easily understood in plain Chinese. All responses were audio recorded in detail and transcribed afterwards. In order to capture details that could not be reflected by audio (for instance, special gestures, facial expressions, or actions), we made observational notes following each interview.

In sum, we collected both effective and less or ineffective leadership events from each participant, which provided discrepant evidence to amplify the validity of concepts being discovered. As Maxwell (2012: 112) pointed out, 'identifying and analyzing discrepant data and negative cases is a key part of the logic of validity testing in qualitative research. Instances that cannot be accounted for by a particular interpretation or explanation can point up important defects in that account'. Thus, the design of the sampling and interview procedures in this study enabled the collection of sufficient and high quality data needed to obtain valid results. In total, 302 competency episodes were included in the analysis.

\section{Data Analysis}

We applied the grounded theory approach in the coding and theory building processes (Corbin \& Strauss, 2008). We extracted competency themes and categories explaining effectiveness by doing a within-subject analysis given that incidents were contextualized. Two well-trained coders, including the first author, worked together on the data analysis. Because this study focused on examining the components and domains of behavioral competencies, we paid careful attention to what the participants thought and felt (cognition and emotion) and did in specific contexts relative to the self and others. Three hundred and two codable competency episodes from the interviews were extracted and compiled for further analysis. Each episode reflected a specific social competency and the self- or otherbased context in which it occurred.

In the initial round of data analysis, the two coders read through all the data, identified the codable competency episodes, and then discussed the potential key concepts together. For the second round of data analysis, one coder coded all the episodes and the second coder coded a sample of $12 \%$ (randomly selected) episodes. For the $1^{\text {st }}$ order themes, the inter-rater reliability was calculated using Krippendorff's Alpha (KALPHA) using the macro by Hayes and Krippendorff (2007) on $12 \%$ of the total episodes (De Swert, 2012; Hallgren, 2012). The 
KALPHA was an acceptable $89.30 \%$. The bootstrapping result indicated that there was only $6.31 \%$ chance that KALPHA would be below .80 if the whole population were to be tested. For the $2^{\text {nd }}$ order concepts, the two coders arrived at an agreement of $91.43 \%$, indicating high consistency between the coders. Finally, discrepancies were discussed until agreements on all themes and concepts were obtained, and the first coder revisited the codes to make relevant revisions.

\section{RESULTS}

Through iterative analyses of the interview data, we identified the emotional and cognitive components of social competence, the self-other domain context, and the influence of social competence of executive leaders in Chinese culture.

\section{Xin (Heart-Mind)-based Social Competencies}

Specific social competencies derived from the data are shown in Figure 1, which illustrates the results of the coding process that we employed. The $1^{\text {st }}$-order analysis included concepts that emerged from interviews, and the $2^{\text {nd }}$-order analysis extracted all of the themes (competencies) derived from the categories that could be used to explain the phenomena. The aggregate dimensions were distilled concept categories based on the $2^{\text {nd }}$-order competency themes (see Figure 1). The Appendix provides example quotes that illustrate each of the competency themes.

The emotional dimension of social competence pertains to the inclusion of feelings, affect and sentiments in intra- and inter-personal interactions (Goleman et al., 2002; Saarni, 1999). Specifically, the data showed six competencies falling under this dimension including affectional bonding, empathic concern, inspiration, supporting to develop others, expressing/regulating emotions, and expressing appreciation. The cognitive dimension of social competence pertains to the inclusion of perception, thought, reasoning and understanding into intraand inter-personal interaction. Six competencies emerged under this dimension including instrumental guanxi, perspective taking, skillful influence, encouraging empowerment and participation, adaptability, and solving conflicts.

According to the theorizing based on the cognitive system of yin-yang balancing, the emotional and cognitive dimensions are the paradoxical and dynamic aspects of social competence, with the cyclical interaction embodied through xin (heartmind), a mixed emotional and cognitive entity. Results in Figure 1 showed that six pairs of the mixed social competencies, with each involving both the cognitive and emotional aspects, emerged from the data. We thus term the mixed social competencies as ' $x$ in (heart-mind)-based social competencies'. Each pair represents a specific aspect of social competence from the emotional and cognitive perspectives, thus they differ but complement each other in forming a holistic component of social competence. We explain each xin-based social competency and its dual emotional and cognitive aspects in detail below. 


\begin{tabular}{l}
\hline Seek emotional support \\
Build an emotional bond with others \\
Create an environment with affect and consideration \\
\hline \hline Build relations as potential resources for cooperation or support \\
Sustain instrumental connections \\
Seek resources and supports \\
\hline \hline Put others' interests first \\
Value differences \\
Improve others' emotional well-being \\
Showcaretoothers \\
\hline \hline Understand others' real situations \\
Understand others' expectations and thoughts \\
\hline \hline Set oneself as a role model \\
Lead employees with vision \\
Encourage others' confidence and efficacy \\
\hline \hline Negotiate with patience, confidence, and strategy \\
Persuade others by being genuine and transparent \\
\hline \\
\hline Provide training to develop individuals \\
Support team development \\
Provide suggestions and ideas for others' development \\
\hline \hline Give authority to colleagues' work \\
Give employees freedom within certain parameters \\
Value emplovee participation \\
\hline Express oneself genuinely \\
\hline Regulate one's emotions in a humble way \\
Regulate other's emotional impulse \\
\hline \hline Make strategic adjustment \\
Be sensitive to environment \\
Adjust one's learning and goals \\
\hline Appreciate the work and contribution of others \\
Appreciate the quality of others \\
\hline Recognize multiple conflicts \\
Solve conflicts in a rational approach \\
\hline
\end{tabular}
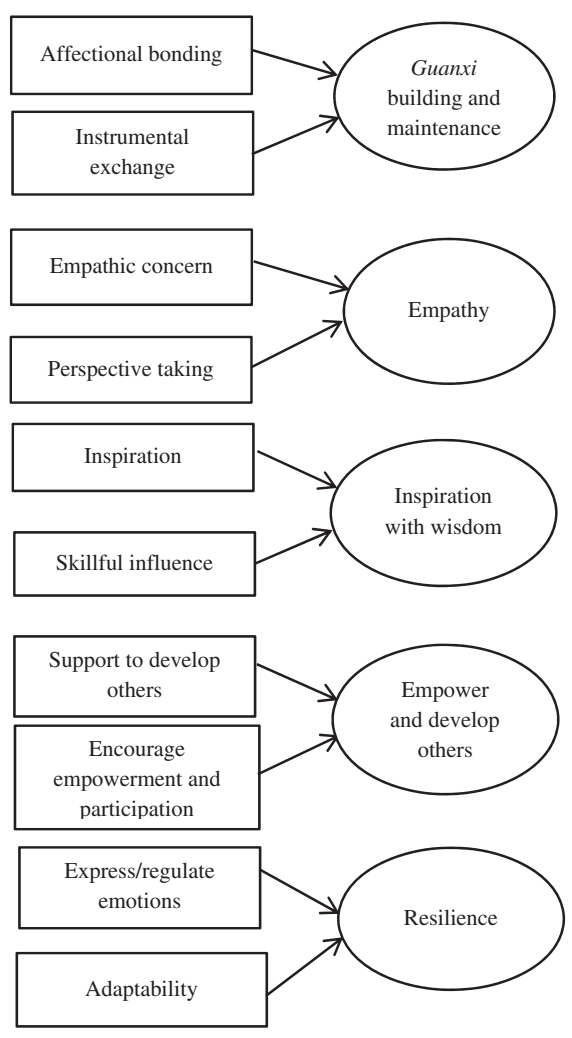

Figure 1. Exemplary coding process of social competence

(1) Guanxi building and maintenance. We suggest that guanxi building and maintenance is a xin (heart-mind)-based social competency of Chinese leaders that reflects various approaches of handling and sustaining social relationships. Based on the formalinformal duality perspective of the social norm, guanxi is defined as 'the Chinese version of social ties (social capital) rooted in the unique institutional context of China with the interplays between weak formal institutions and strong informal ones in the history of China' (Li, 2007a: 65) and as 'an informal norm of social ties that regulates and facilitates the privileged access to personalized exchange at both dyadic and network levels' (Li, 2007a: 66). In Chinese culture, the instrumental and sentimental roles are integrated into the kin and non-kin guanxi capital (Li, 2007a). Studies have examined the importance of guanxi in leadership in Chinese culture (e.g., Song, Cadsby, \& Bi, 2012; Xin \& Pearce, 1996) yet little is known about the cognitive (instrumental) and affective (sentimental) components of guanxi building 
and maintenance. As research points out that trust as a social concept includes two elements - cognition-based trust and affect-based trust (McAllister, 1995) - guanxi building and maintenance as a similar social concept can been more sufficiently explained with both cognitive and emotional aspects. Based on $\operatorname{Li}(2007,2008)$ and Chua, Morris, and Ingram (2009) studies on trust, affect-based trust and cognitionbased trust were not easily differentiated in Chinese culture. However, the high correlation between these two aspects does not mean they are not distinguished. As noted earlier, Zhang, Liu, and Liu (2015) found that cognition-based and affect-based trust generated different impacts. Given it is possible that the two elements of guanxi may generate different impacts on social interaction, we consider guanxi building and maintenance as a combination of two elements. Hwang (1999) actually differentiated guanxi into expressive and instrumental components, yet little is known about how the emotional and cognitive aspects of guanxi building and maintenance are demonstrated by top executive leaders. Given the themes that emerged from the data, we consider that affectional bonding and instrumental exchange represent two paradoxical and dynamic aspects of guanxi building and maintenance, and the two aspects together support guanxi building and maintenance as a mixed emotional and cognitive social competency.

Affectional bonding indicates an executive leader's competency of building an emotional and affective bond when interacting with people in and outside of the organization. It was originally used to describe the bond between parents and infants (Bowlby, 1958), which was characterized by being stable, loving, long term, and fundamental. Subsequently, it was expanded to describe behavioral relationships such as sexual pair bonds, friendships, and kinship bonds (Ainsworth, 1989). In this study, affectional bonding is indicated when an executive creates an atmosphere of care and consideration for others by organizing various fun activities, demonstrates compassion to specific individuals to produce a quasi-family feeling and build an emotional bond with them, and seeks emotional support from others. This competency plays an important role in leadership and organizing, as a CEO from a fire extinguisher service company in our sample described:

We built up an online web. In this way, we hope to strengthen their [the employees'] feelings to the organization. Others said that my company almost became an entertainment company. By organizing such activities every three months, we incorporated a lot of ideas. For the evening party, people all wear full dresses, which some of them never wore in their whole life. Once he or she wore the dress, he or she experienced some changes and showed longings for beautiful things. I just want to imbue them with such affection and emotions... By doing all these things, I make everybody feel pleasant in the company.

Instrumental exchange reflects the instrumental or rational aspect of guanxi building and maintenance. Hwang (1999) defined the instrumental component of guanxi as 'the fact that as biological organisms, people have a variety of innate desires, and 
they must interact with others in an instrumental manner to obtain the resources required to satisfy these desires' (167), but his viewpoint was based on analyses of ordinary people and their family relationships. In this study we specifically use instrumental exchange to refer to the cognitive aspect of a top executive leader's social ties with others. As shown in the data, it is indicated when an executive builds personal relations with others as potential resources for cooperation or support, sustains instrumental connections with people inside or outside of the organization, and seeks resources and support by displaying friendship and support. For instance, a CEO from a construction company said,

All those working in engineering are basically from a circle of acquaintances, including our project department. I built up a project department, which was led by my project manager. He came to hire employees, the criteria he saw was with whom he had contacts.

Although affectional bonding and instrumental exchange may represent two sides of the same construct - guanxi building and maintenance - differences do exist. As our data show, affectional bonding focuses on building an emotional bond with others and promoting the enjoyment, happiness, and commitment of others through creating an environment with affect and consideration, while instrumental exchange stresses the instrumental purpose of social ties such as seeking resources and building and sustaining instrumental transactions. Thus, the intent of instrumental exchange is to extend and develop one's social capital and gather potential resources for present and future benefits, while affectional bonding demonstrates one's care and consideration towards others to create shared meaning and to form collective identity.

(2) Empathy. We suggest that a second xin (heart-mind) social competency of Chinese executive leaders is empathy. In western writings, researchers have defined empathy as a multidimensional concept including both affective and cognitive components (e.g., Davis, 1983). Data in this study further confirm empathy as a mixed emotional and cognitive social competency. Empathic concern and perspective taking represent two aspects of a multidimensional empathy construct from emotional and cognitive perspectives. These two aspects of empathy are correlated but distinct (Galinsky, Maddux, Gilin, \& White, 2008), with those who are better at perspective taking having an advantage at recognizing people in need of help and thus offering a more effective response than those poorer at perspective taking (Lamm, Batson, \& Decety, 2007). In this case, perspective taking may serve as an antecedent of empathic concern over others. Thus we may understand perspective taking and empathic concern as two paradoxical sides of empathy, with the former as a cognitive antecedent of the latter.

Empathic concern has been considered as an important social competency relating to prosocial behavior (Eisenberg \& Fabes, 1990; Reynolds \& Scott, 1999). It 
demonstrates the affective aspect of experiencing other's feelings and caring about them. According to the data, an executive leader indicates empathic concern when he or she puts others' interest first, values differences, improves others' emotional well-being, and shows care and consideration to others. A CEO from a fitness equipment company explained,

I care about employees' workplace happiness. Employees experience happiness when they love the job. I let them enjoy themselves in completing their work everyday and in ordering products accurately. [In this case], they take work as a pleasure.

Perspective taking refers to standing in another person's place to understand their needs, preferences, and values (Parker \& Axtell, 2001). It is defined as a cognitive process and promoted by prosocial motivation (Grant \& Berry, 2011). As shown in our data, it is indicated when an executive leader intends to understand other's real situations, expectations and thoughts. For example, as an executive leader shared a part of her conversation with another executive leader in the company,

Ms. [Name] is a Gemini. If she feels pressure, she will deliver that to us. When she complains in front of you, she wants us to know her work is not easy. But she is in a very good position, she gets the most share of interests and she can work for it like a home. She thinks of me as an incredible resource, because she used to work for a foreign enterprise and earned 2 million per year at the most, but now there is no upper limit here. Why is she not happy with it? I said no way. She wants to spend money to extend the business but also has a concern of not using the money because she is new here and that's why she is complaining.

(3) Inspiration with wisdom. The concept of inspiration with wisdom captures both emotional and cognitive meanings of xin (heart-mind)-based social competencies. Chinese culture emphasizes wisdom $(z h i)$ in handling social relationships, defined as the application of benevolence (ren), righteousness $(y l)$, and propriety $(l i)$ in social interaction (Hwang, 2015). Research on paternalistic leadership in the Chinese culture reflected both the traditional authoritarian characteristic and also the modern benevolence of Chinese leaders (Cheng, Chou, Wu, Huang, \& Farh, 2004). A leader's skillful influence involves wisdom as a core part. Yet few studies have integrated both cognitive competency of skillful influence and the emotional competency of inspiration, which partially contradict and partially complement each other.

Inspiration in leadership has accumulated attention over recent years (Bass, 1999). Our data shows that inspiration is indicated when an executive leads employees with a promising vision, encourages others' confidence and efficacy, and acts as a role model. For example, an executive in our sample inspired his employees' enthusiasm in creativity, 
He needs to make a product and work on our platform. I give him the space. He has lot of experience. I told him 'I do not have technology background but I understand customer needs. I just want to create a platform for everybody. You have the power and authority at this platform. At first you need to tell me what you are going to do and what you will demonstrate to customers, then the platform is yours. He is longing for this.

Skillful influence reflects one's competency to persuade or influence others in order to reach certain goals. As the data show, it is indicated when an executive leader negotiates with patience, confidence and strategy in order to arrive at a deal or certain goals, and persuades others by being genuine and transparent. In negotiating with a business partner, an executive from a paint company mentioned how he skillfully persuaded his business partner to support his business,

At that time, the German [Company] had been in China for 18 years, but I told him [the CEO of Company in Germany], 'the business operation of your [Company] in China was very poor and I have the ability to improve your brand, but I need shares, your product technique and money support'. Its product technique is considered exquisite worldwide. I just wanted its technique and I would re-operate it in China and this would have no relationship with him. I rebuilt my team and I calculated the interests of my previous small enterprise. According to the international acquisition, 8 times of my small enterprise was worthy of 24 million yuan, and my annual salary was several million and if I joined the shareholder for 5 years, I would earn 40 million. And I negotiated with him this way.

(4) Empowering and developing others. We suggest that empowering and developing others is a fourth xin (heart-mind)-based social competency of Chinese leaders. This concept indicates that effective leaders not only empower followers and engage their participation, but also provide encouragement and emotional support for their development and learning. As a recent study on leadership effectiveness in Chinese culture found, effective Chinese leaders in modern society had a shift in values from traditional authoritarian management to those emphasizing participation; meanwhile, effective Chinese leaders were perceived as employing behaviors of being supportive, caring, and responsible (Wang, 2011). This mixed emotional and cognitive social competency is also aligned with servant leadership (van Dierendonck, 2011). While little previous research has explored the relationship between leader empowerment and developing others, our data suggest that supporting to develop others and encouraging empowerment and participation reflect the paradoxical interaction between emotional and cognitive elements of empowering and developing others.

Supporting to develop others is considered as an important competency of leaders in recent research on coaching and employee and team development (Boyatzis, 
Smith, \& Blaize, 2006; Conger, Kanungo, \& Menon, 2000). Effective leaders value the development of employees and teams and actively create an atmosphere benefiting employee development (Wang, 2011), which also increases employee commitment and team performance (van Dierendonck, 2011). As this study's data indicates, this competency is indicated when an executive leader provides training to develop individuals, supports team development, and provides suggestions and ideas for others' development. Below is an example from an executive leader in a construction company,

I talked to employees in advance about what they should learn from the training. This was not just about knowledge, but also how you marketed yourself and let more of your leaders and colleagues remember you. Only by letting others remember you can you have opportunities. Thus "you have to demonstrate your value". I told them in advance at what level the conference was, what they should notice, and what they should do there. I made a request of them in advance. If I did not request anything, they would just go there and listen. They would say it was good. However, I not only expected them to listen, but also to express their opinions and let others know he/she was a person with thoughts. If you did not remind him/her, he or she may not know this.

Encouraging empowerment and participation is another competency shown in the data. Contrary to hierarchical authoritarianism, a leader's empowerment and engagement of employees is a way to foster their self-confidence and develop their sense of personal efficacy (van Dierendonck, 2011). It is indicated when an executive leader gives authority to a colleague's work, gives employees freedom within certain parameters, and values employee participation. An executive mentioned the following when reflecting on his own experience,

I still want to weaken my responsibility. My experience in recent years informs me that whenever I weaken myself [my power], they [my employees] all become excellent performers, including my experience in the previous organization, all my employees are better than me [in expertise]. I told them, 'you are an expert in this field, so you are the boss; be courageous with your idea'. After all, they all are experts and I am not.

(5) Resilience. The fifth xin-based social competency of Chinese leaders is resilience. Resilience is defined as 'growth or adaptation through disruption rather than just to recover or bounce back' (Richardson, 2002: 313). This concept suggests that effective leaders not only adapt to situational change, but also manage their own or others' emotions appropriately when faced with change. Adaptability is considered as a significant form of regulation (e.g., self-regulation) (Day, 2000). Adapting to different cultures and organizations is essential for adaptive performance (Black, 1990). Expressing and regulating emotions appropriately reflects regulation of one's own or others' emotions to generate more flexible and adaptive behaviors (Wong \& Law, 2002). Thus we suggest that expressing/regulating 
emotions appropriately and adaptability complement each other in representing the emotional and cognitive aspects of resilience.

Expressing and regulating emotions appropriately has been confirmed as an important component of emotional intelligence in previous studies (Kark \& Van Dijk, 2007; Mayer, DiPaolo, \& Salovey, 1990; Van Kleef, Homan, Beersma, Van Knippenberg, Van Knippenberg, \& Damen, 2009). In accord with our earlier argument that the social competence of leaders is contextualized and conditional, an effective executive leader expresses and regulates emotions appropriately when faced with difficult situations and change. It is indicated when an executive leader expresses him- or herself genuinely, regulates his or her own emotions in a humble way, and regulates others' emotional impulses for their personal or organizational development. An executive leader from a smart toy company showed how this competency was demonstrated when dealing with difficult customers,

When this customer was angry, I basically did not respond, I simply removed him from the chat group and did not let his impulse impact others. Some people may think - why are you so bad? Well, I think when a child is crying, instead of persuading him not to cry, we give him or her a place to cool down. I left him a message 'Mr. [Name], we have removed you out of our group and will communicate and invite you back following our private communication. Thank you for understanding'! Then what I did was to calm him down and extend the time to make a response.

Adaptability reflects the leader's ability to make adjustments when the situation changes. It has been shown to estimate job performance, including managerial performance, across multiple jobs, occupations, and industries (Clark, 2000; Pulakos, Arad, Donovan, \& Plamondon, 2000). In this study's data it is indicated when a leader makes a strategic adjustment, is sensitive to the environment, and adjusts their learning and goals. An executive from the software industry in our sample said,

We looked for core research and development, but could not get anything. Why? Nobody wanted to do it. At the end of the year, employees told me, 'because of various evaluations, after several rounds of assessment, everybody feels the pressure and there is not a comfortable environment'. Thus, in the following year, we adjusted the strategy. [I said], if you don't like it, you can work on something yourself and bring your results to me.

(6) Appreciative problem solving. A sixth xin (heart-mind) based social competency of Chinese leaders is appreciative problem solving. Traditional problem solving methodology emphasizes the rational investigation and identification of problems and causes, while appreciative problem solving integrates appreciative inquiry into the problem solving that stresses the strength and positive image in a futureoriented changing process (Cooperrider, Whitney, \& Stavros, 2003; Peele, 2006). 
Appreciative problem solving indicates that effective leaders are not only good at recognizing and handling conflicts, but also at appreciating the positive side of others. The two competencies of expressing appreciation and solving conflicts thus represent paradoxical viewpoints of how effective leaders lead in situations of change.

Expressing appreciation reflects gratitude, admiration and respect for others' work, contribution, and qualities. People have the need to be recognized and acknowledged, and thus for an executive leader it is important to appreciate what others do and express this authentically to them in social interactions. As shown in this study's data, this competency is indicated when an executive leader appreciates the work, the quality and characteristics of others. A CEO of a company in the training industry in our sample described,

I want to throw him out of the company several times and I think there will be no difference between throwing him out and playing with him. I still appreciate his insistence. I feel I am not anxious when he is here. I can be famous without creating this company, but he cannot. He cannot let it go and he is very determined. I cannot only tell whether he treats me well but also see his qualities. He has good qualities. He is cunning and has lots of issues, but his nature is good and he is a person with love, which I hold dear.

Solving conflicts with effective approaches reflects the social competency of conflict resolution in leadership and organizing. It is indicated when a leader recognizes multiple conflicts, and solves conflicts in a rational approach. Differing from some other studies which claim that Chinese culture emphasizes conflict avoidance (Kirkbride, Tang, \& Westwood, 1991; Leung, 1988), effective Chinese executive leaders in this study demonstrated the competency of conflict solving. For instance, an executive in a construction company illustrated what he did when he solved a conflict between employees,

I recruited a new employee as my vice president. But he did not do a good job and some people had opinions towards him. When they brought this up, I told them, 'you have to respect him. If he does not handle this issue appropriately, let's talk about it then'. Then I told my vice president that he needed to write a statement and he had to be involved in this community first. I communicated with them this way [to solve their conflict].

\section{The Self and Other Domains as the Context for Social Competence}

The data analyzed for the present study revealed different pairs of self and other domains, which constituted the contexts for leaders' demonstration of social competence. As described in Figure 2, the self was expressed as both the individual self (I) and the organizational self (we), each embedded in a specific relational 


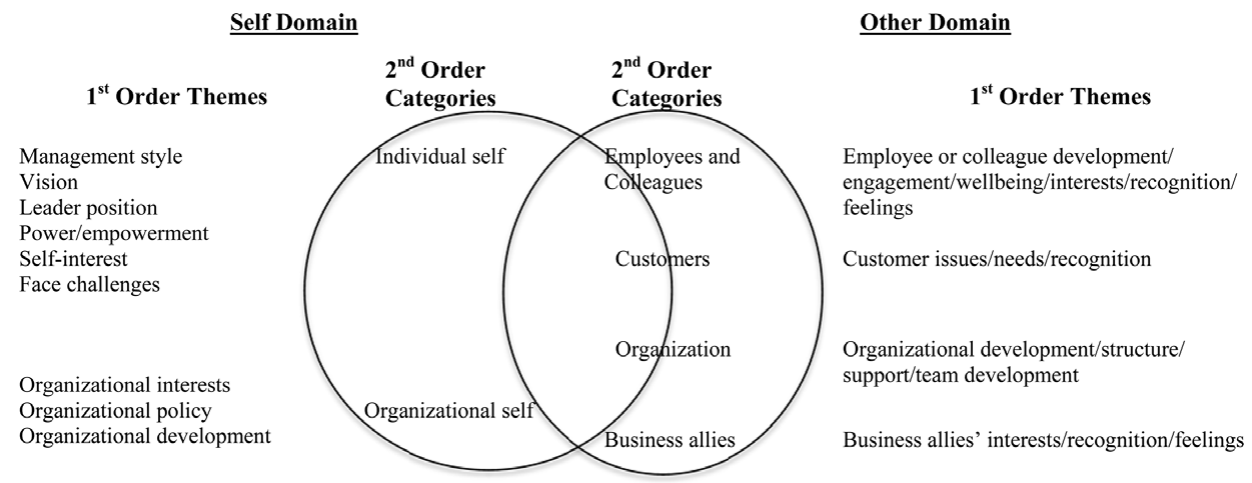

Figure 2. Exemplary coding of social context

Notes: The left circle represents the two roles of the executive leader self (self domain). The right circle represents the parties within the other domain. The overlap between the two circles represents the interaction between self and other domains.

context interacting with others. As indicated in Figure 2, the $1^{\text {st }}$ order concepts representing individual self (I) included management style, vision, leader position, power and empowerment, self-interest, and facing challenges. The $1^{\text {st }}$ order concepts representing the organizational self (we) included organizational interests, policy, and development. The other domain was summarized as employees and colleagues (i.e., development, engagement, well-being, interests, recognition, and feelings), customers (i.e., issues, needs, and recognition), organization (i.e., development, structure, support, and team development), and business allies (i.e., interests, recognition, and feelings). Drawing on leader identity and role theory (Stryker \& Burke, 2000) and construal level theory (Reyt \& Wiesenfeld, 2015), we suggest that a top executive leader's behavior reflects his or her work roles at both the individual and collective levels. Thus a top executive leader does not only represent him/herself as an individual but also the organization at the collective level. As an individual self, an executive leader is symbolized with the individual identity expressed as 'I'. As an organizational self, an executive leader's collective identity can be expressed as 'we'. Research finds that top executive leaders in a collectivist culture (such as Chinese culture) tend to use 'we' when describing his or her role and responsibility, because collectivism increases people's feeling of obligation and duties (Triandis \& Suh, 2002).

How are the two roles of a top executive leader accomplished? As the present study's data showed, categories of the collective self and the other consistently reflected how the executive leader was epitomized in social activities as a collective self, that is, activities which exist in the interaction between the collective self and others. For instance, a female executive leader mentioned, 'we explained to all the people [employees]. Because the company did not have that [the empowerment document] before, everybody did not show interest in it. Later on we found employees did not have many opinions, so we emailed to everybody and requested them to provide comments in a paper format within a certain period of time. If not, 
we would take it as acceptance'. This executive leader was responsible to create and carry out the empowerment document among employees, but she put herself in the organizational position. Instead of describing how she individually leads, she reframed herself as a part of 'we'. In another instance, the individual self, I, was epitomized in the social activities between the individual self and others. For instance, an executive leader elaborated, 'my friend was also his friend. We all had dinner together and mentioned that my business was in this field. He asked me how to design that project and I honestly expressed my viewpoint. He said 'if I should give the money to the construction partner, would you suggest me to do this'? I answered 'if you should pay the money, pay it'. The following day he contacted me and said he would like to offer me a project'. When an executive leader interacted with others (i.e., employees, customers, business allies, and the organization), the intention was mainly for others' well-being, team building, development and interests etc. For executive leaders immersing the self (i.e., organizational and individual self) into social activities involving the employees, customers, business allies, and organizations, the demonstration of their social competence is more likely to lead to positive outcomes.

\section{Outcomes of Social Competence}

Results of each episode in the data were also coded to represent the outcomes of social competence in leadership effectiveness in different contexts (see the Appendix for sample quotes). These results are summarized as four categories (Figure 3).

Customer relevant. Customer relevant outcomes are demonstrated as customer relationship and satisfaction. For example, an executive leader in the paper industry explained how he took a customer's perspective and delivered the right products even though the customer had signed off on the wrong products. He said in the end 'through this business, the customer has been a very reliable customer through all these years. Beyond being an honest customer, he also introduces lots of businesses to us. When our employees go to visit other customers, he directs our employees to the right place'.

Employee relevant. Employee relevant outcomes are indicated as employee performance, satisfaction, and well-being. An example is that an executive leader shared his similar experience and thoughts with employees. He found that employees enjoyed talking with him and through this began liking their work. He said 'they expect to advance in their work instead of taking it as a disaster, not like employees in some organizations who desire the weekend all the time and hate the time going by so slow'. This executive changed employees' feelings about their work from hatred to enjoyment. 


\begin{tabular}{|c|}
\hline $\begin{array}{l}\text { Trust and cooperation with customers } \\
\text { Sustain customer relationship }\end{array}$ \\
\hline $\begin{array}{l}\text { Customer satisfaction } \\
\text { Attract customer interests }\end{array}$ \\
\hline $\begin{array}{l}\text { Employee work engagement } \\
\text { Employee performance improved }\end{array}$ \\
\hline $\begin{array}{l}\text { Employee commitment to the organization } \\
\text { Employee trust in the organization } \\
\text { Perceived follower satisfaction }\end{array}$ \\
\hline $\begin{array}{l}\text { Employee well-being improved } \\
\text { Employee stability } \\
\text { Employee self-autonomy improved }\end{array}$ \\
\hline $\begin{array}{l}\text { Self emotional well-being } \\
\text { Self improvement }\end{array}$ \\
\hline $\begin{array}{l}\text { Acknowledgement from others } \\
\text { Satisfaction with the outcomes }\end{array}$ \\
\hline $\begin{array}{l}\text { Organizational improvement } \\
\text { Enactment/improvement of organizational policy } \\
\text { Organizational change in a good direction } \\
\text { Organizational structure adjustment }\end{array}$ \\
\hline $\begin{array}{l}\text { Product sales } \\
\text { Enrich products } \\
\text { Finish project in time } \\
\text { Come up with a project plan }\end{array}$ \\
\hline
\end{tabular}
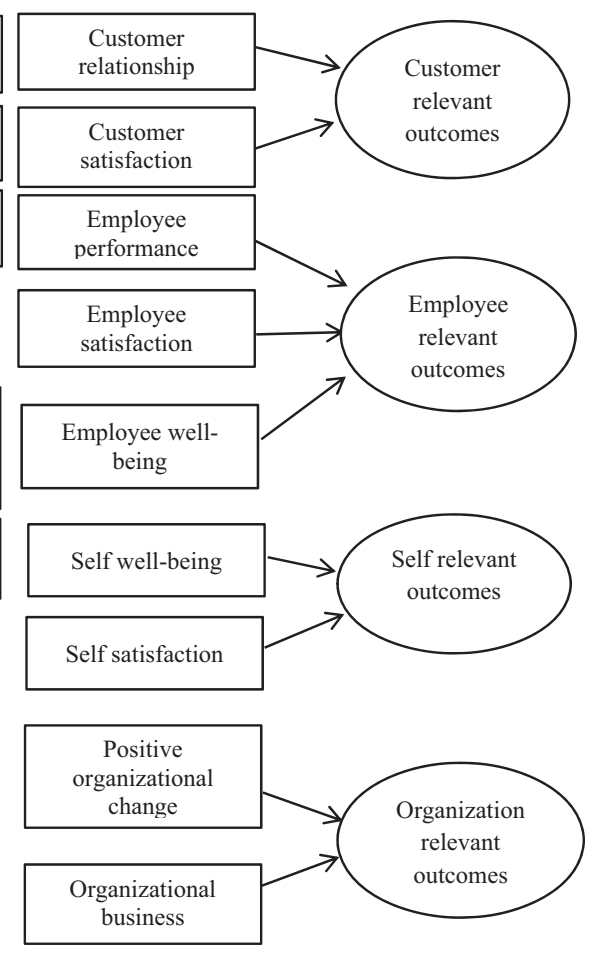

Figure 3. Exemplary coding process of outcomes of social competence

Self-relevant. Self-relevant outcomes are indicated as self-well-being and satisfaction. An executive leader shared his leadership and life philosophy and how this impacted himself. He said, 'I really like this way of leading and living. With this approach, I continuously decrease my own pressure and feel so relieved on a lot of things. I have also learned how to empower others'.

Organization relevant. Organization relevant outcomes are expressed as organizational change and development. An executive leader shared his experience of getting into a new business and how the company was developed in the process. He said, 'after getting into this business, our company had about 120 employees and we opened five branches over the country. And building on our previous cooperation with business allies, there would be quite a possibility of having continuous projects with them'.

\section{DISGUSSION}

By investigating Chinese executive leaders' emotional and cognitive competencies from a behavioral perspective, this study aimed to uncover social competence and 


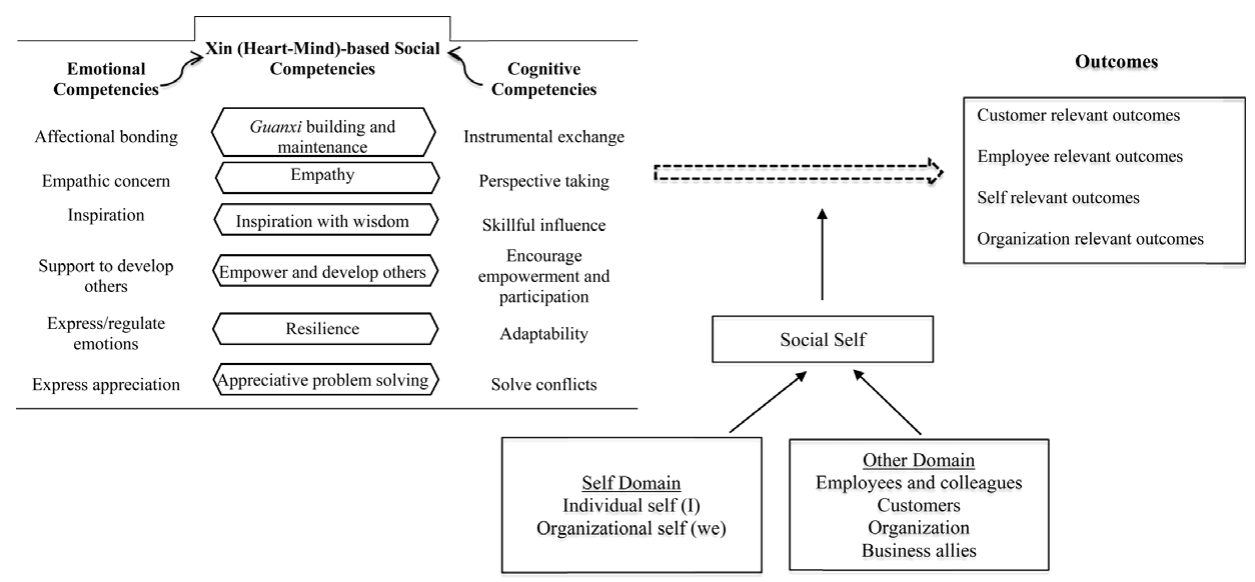

Figure 4. An integrative framework of leaders' social competence in the Chinese cultural context

its internal structure related to leader effectiveness in Chinese culture. We identified six emotional components of social competence and six cognitive components of social competence, which together comprise six paradoxical and dynamic pairs of xin (heart-mind)-based social competencies. The contexts where social competence is demonstrated include the self and the other domains. The relationship between the emotional and cognitive components of social competence on the one hand and the self and the other domains on the other hand enriches our understanding of social competence as conditional upon the specific context involving both the leaders and others.

\section{An Integrative Framework of Social Competence}

As shown in Figure 4, we develop an integrative framework following a grounded approach to illustrate the relationships among the concepts and categories that emerged from the data. As noted, the two paradoxical dimensions of leaders' social competence - emotional and cognitive social competence - were integrated as six xin-based social competencies, which were the dynamic and cyclical effects of six pairs of emotional and cognitive social competencies. Zhu (2013) pointed out that Chinese entrepreneurs have to 'deal with the dilemma relating to qing (positive emotions) and $l i$ (rationality) holistically to reach a balanced outcome in their everyday business practices' (613). The xin-based social competencies absorb the advantages of both emotional and cognitive competence and thus are expected to lead to leadership effectiveness. Previous research has pointed out the significant impact of emotional and cognitive competence on leadership effectiveness (Goleman et al., 2002; Hollenbeck et al., 2006). The competency episodes in this study not only indicated the partially conflicting and partially competing emotional or cognitive aspects of social competence, but also the influence of social competence on leadership effectiveness. Thus we propose: 
Proposition 1: Xin-based social competencies of top executive leaders, integrating paradoxical emotional and cognitive aspects, will predict leadership effectiveness.

Further, the self and other domains serve as the contexts and foundation where social competence is demonstrated (Rose-Krasnor, 1997). As the data showed, the self-domain was embedded in and interacted with the other domain to contextualize the demonstration of specific social competencies. This finding further supports the argument that in Chinese culture, the self and the other are not isolated but closely related, with the self-embedded in interaction with others (Chuang et al., 2015; Tu, 1995). Thus, the interaction between the self-domain and other domain which we termed as 'the social self' in Figure 4 moderates the relationship between social competence and leadership effectiveness. We expect that social competence will have a stronger positive impact on leadership effectiveness for executive leaders with a stronger demonstration of the social self. Specifically, when leaders exhibit themselves as a social self at both the individual and organizational levels, that is, embedding themselves in social relation with others, the relationship between social competence and leader effectiveness will be stronger.

Proposition 2: The self and the other domains will interactively moderate the relationship between social competence and leadership effectiveness.

\section{Theoretical Implications}

The major theoretical contribution of the study is that we specify the internal structure of the social competence of leaders in indigenous Chinese culture, which can be explained from the following points. First, we inductively examine the elements of social competence relevant to leader effectiveness in Chinese culture. With the interview data, we find social competencies contribute to leaders' effectiveness in Chinese culture and interpret the meaning of each by referring to specific quotes, which increases our understanding of Chinese leaders' social competence. From the meanings of specific social competencies, we infer that Confucian thoughts of ren set the foundation for specific social competencies involving caring, consideration and cultivation of others such as supporting to develop others, empathic concern, affectional bonding, and inspiration. Yet, with the economic development and change in China, some traditional thoughts may have been evolved and thus social competencies we find in this study also reflect the most recent status in China. For instance, people mostly think that in the hierarchical system of a private Chinese enterprise, executives are vested with legitimate authority and tend to express their emotions in a top-down way in order to claim their power over subordinates (Cheng et al., 2004). However, we find that except for applying their cognitive competencies, effective leaders also tend to empower followers, express their 
emotions appropriately, and regulate their emotions suitably for the situations they face.

Building on the above point, an indigenous perspective of the cognitive system of yin-yang advances our understanding of a balancing of cognitive competencies more traditionally valued as well as emotional competencies that reflect the changing nature of the economy. Research based on Western culture has acknowledged the emotional and cognitive dimensions of social competence (Goleman et al., 2002; Yeates \& Selman, 1989), but little is known in terms of how the two dimensions are connected. The cognitive system of yin-yang balancing aids our understanding of the two dimensions from a paradoxical perspective, especially the nuanced interaction between the two dimensions. Specifically, the emotional and cognitive dimensions differ from each other in terms of representing specific social competencies from different perspectives, yet they also complement each other in forming a coherent and holistic entity. Thus, each specific xin-based social competency is a dynamic and cyclical consequence of a paradoxical pair of emotional and cognitive elements. Our findings show six pairs of xin-based social competencies that result from the dynamic interaction between the two dimensions. The xin cultivation system stimulates the dynamic interaction between the emotional and cognitive dimensions.

Third, this study clarifies the self and other domains and their relationship to social competence. In an individualist culture, the self and other domains are considered as separated (Bakan, 1966; Behhah et al., 2007) and thus a 2x2 framework of social competence may be claimed (i.e., cognitive/emotion $\mathrm{x}$ self/other). However, in the present study we find that in the collectivist Chinese culture, the self and other dimensions mutually form the social context of social competence. For each episode where a social competency is demonstrated, there is a specific context composed of both self and other elements. Thus, the self is a social self and exists in the relation to others (Chuang et al., 2015; Markus \& Kitayama, 1991) and we cannot differentiate the self and other into separate categories. Further, as an extension to leader role and identity theory, we find that both the individual role and the organizational role of an executive leader are accomplished in social activities involving others.

Fourth, this study enriches our understanding of guanxi building and maintenance, especially its internal structure, and also contributes to the development of emotion in leadership studies in Chinese culture. Research has confirmed the importance of guanxi as an indigenous norm of social capital in interpersonal relationship building in Chinese culture and analyzed its components and structures from a duality perspective (Li, 2007a), but insufficient work has been done to explore specific cognition-based and emotion-based aspects of guanxi as social capital, as previous researchers have developed about trust (Li, 2008; McAllister, 1995). In the present study, affectional bonding and instrumental exchange as two aspects of guanxi building and maintenance emerged from the data. Affectional bonding offers a distinctive perspective of bringing affection 
and humanity into the workplace. Instrumental exchange similarly extends the leader's instrumental networking by building social relations with others. These two concepts call for further study on the paradoxical structural components of guanxi building and maintenance and other similar social constructs in the Chinese culture.

\section{Practical Implications}

This study has important implications for the leadership of top executives. As top executive leaders, their role identity informs that they are not only individual persons but also represent the organization, which may implicitly increase their felt obligations and expectations from others. In this situation social competence is even more important, because leaders can manage their own intentions, job requirements, and expectations from others by effectively applying cognitive or emotional social competencies. In addition, the findings of the present study also provide practical guidance for leadership education and competency development of Chinese executives. There are different approaches to develop social competencies. Through professional training and learning, leaders can learn the meanings of these competencies; and through self-cultivation or self-development, leaders can better practice these competencies and build a harmonious relationship between themselves and others (Chuang et al., 2015; Hwang, 2011). Further, the findings may inform expatriate managers sent to China - a pre-training or study of these social competencies might help them acculturate more quickly.

\section{Limitations and Future Research Directions}

The limitations of this study are as follows. First, the critical incident interview methodology assumes that participants provide incidents that are critical to explain their effectiveness. It is possible however that the incidents selected by participants may fail to explain leadership effectiveness or that the behaviors described do not reflect relevant underlying competencies. To mitigate against this possibility, during the data collection procedure we paid special attention to this challenge of the critical incident interview approach and intentionally led participants to describe their behaviors within a whole event setting.

Second, as with all exploratory studies, the generalization of the findings is also a concern. We studied 42 participants from SMPEs of various industries in four northern Chinese cities, and thus the findings may not be generalizable to other types of enterprises or enterprises from other parts of China. However, given that social competence represents people's competencies in social interaction, the behaviors predicting leader effectiveness are more likely to be stable across industries and occupations under the same cultural context. 
One future research direction is to explore the transactional and transformational meaning of social competence. According to the definition, competence has the characteristics of being transactional, contextual-dependent, ongoing organizing, observable, and essentially linking to effectiveness (Boyatzis, 2009; Rose-Krasnor, 1997). However, we have concerns in terms of the transactional characterization of social competence. First, since social competence evolves contextually, it may be limiting to define it as merely transactional. As shown in recent research on the leader-follower relationship, the interaction between them could be transactional or transformational (Avolio \& Bass, 1995). Thus social competence, as the interaction between people in a social context, could be transactional or transformational especially in a social culture like China which emphasizes guanxi, networks and hierarchy (Ghen \& Chen, 2004). More importantly, taking transformational characteristics into consideration such as time, change, and growth can enrich social interactions. Second, recent research on leadership pays increasing attention to transformational leadership, which has been shown to be more effective than transactional leadership (Bass, Avolio, \& Atwater, 1996; Brown \& Moshavi, 2005). With this in mind, we also encourage the exploration of the transformational features of social competence, which not only reside in social interactions but also improve the relationships.

Third, as another direction to further examine and generalize the findings in the current study, we encourage future research to collect data from a wider swath of enterprises, particularly Chinese state-owned enterprises (SOEs) and multinational companies (MNCs). We may thus see whether and how different sub-cultures within the Chinese culture impact the content of social competence. Finally, in a recent West-based competency study, gender differences in emotional and social competencies were associated with an executive's perceived effectiveness (Hopkins \& Bilimoria, 2008). Given that only a few female executives were included in the present study's Chinese sample, we were unable to assess gender effects in this study, but recommend that gender differences in the social competence of Chinese executives be studied in future research. 


\section{APPENDIX I}

\section{Sample Quotes of Social Competence and Outcomes}

Competency Theme Sample quotes

Instrumental Build relations as potential resources for cooperation or support

exchange $\quad$ He [customer] paid the money and we delivered the goods to him. He got the goods the same night. But the products were different as what he needed. It turned out that we delivered the wrong goods and he could not use them. What should we do? At that time, some people in my company said, 'it is such a long distance and he does not place a big order and we can totally ignore it. We get the money anyway'. Some others said, 'it's late night now. We have to wait till tomorrow even if we change the goods for him'. However, the customer said he was in dire need of the goods and requested as to think of a way to solve the issue. Then there was an intense argument [in my organization], I just hired a truck and delivered the goods to [the customer] again. Certainly we could not earn money and made this business by losing money. Everybody did not understand in the beginning why I did this business even with losing money. However they understood afterwards. Through this business, he [customer] has been a very reliable customer through all these years. He is not only an honest customer, but also introduces lots of businesses to us. When our employees go to visit other customers, he directs our employees to the right place. [LB]

Sustain instrumental connections

The work efficiency can be productive only when [employees'] families are stable and happy. The end of work is for family business.

[Employees'] work can be more stable only when they have a happy family. It's the same for the middle and top levels of managers. Only so can they be more accountable in work. We have 70 middle and top managers. I communicate with two of them everyday, in order to create a harmonious relationship among all of them and to avoid being distanced with each other. I can learn about their thoughts and deliver my thoughts to them. [GP]

\section{Seek resources and supports}

Mr. [Name] is the officer in charge for that project. He is a senior design engineer in Inner Mongolia. People from his times have very good virtues, responsible and indigenous. We invited him to be our consultant to guide us in the field. When I visited him, he was just after the eye surgery and he said he could not be in the field. After I visited him for several times [he said yes to help us]; I did not even know Mr. [Name] before this. I hope I can learn more from Mr. [Name] about the field management. [MX] 


Competency Theme Sample quotes

\section{Skillful influence $\quad$ Negotiate with patience, confidence, and strategy}

At that time, the Germany [Company] had been in China for 18 years, but I told him [the CEO of Company in Germany], 'the business operation of your [Company] in China was very poor and I have the ability to improve your brand, but I need shares, your product technique and money support', Its product technique is considered exquisite worldwide. I just wanted its technique and I would re-operate it in China and this would have no relationship with him. I rebuilt my team and I calculated the interests of my previous small enterprise. According to the international acquisition, 8 times of my small enterprise was worthy of 24 million yuan, and my annual salary was several million and if I joined the shareholder for 5 years, I would earn 40 million. And I negotiated with him this way. [WT]

Persuade others by being genuine and transparent

The subsidiary company's CEO would doubt this project. For all those we returned their money, we told them, 'there is no problem with the system stability and the time to wipe cards is from 7-9am. You can still use the product and we suggest you to use it. If you cannot really use it, we will return you all the money'. [CG]

Adaptability

Make strategic adjustment

We looked for core research and development, but could not get anything. Why? Nobody wanted to do it. In the end of the year, employees told me, 'because of various evaluation, after several rounds of assessment, everybody feels the pressure and there is not a comfortable environment'. Thus, in the following year, we adjusted the strategy. [I said], if you don't like it, you can work on something yourself and bring your results to me. [Q]]

Be sensitive to environment

Because the project manager and our company were very anxious and nervous when knew [this accident] and did not know how to handle it. So I had to make a plan right away. Under my guidance, we got the issue under control and handled it well afterwards. I remember I made three decisions: first, control the situation in the scene; second, all the construction workers should not leave the field; third, handle other relevant things and cooperate with fire fighters to cease the fire. Then [my employees] worked as I directed. I think that no matter an organization or a project, if there is a big issue happening, no mater significant or minor, you need to know how to handle it and come up with ideas, to take the responsibility. [WQ]

Adjust one's learning and goals

When I worked on that [project], I could tell whether I should hit goal 1, 2, 3, or 4. Arriving at goal 4 may benefit the company but hurt myself harshly; maybe after finishing the project, I had to leave the company. In this case, I may just target at goal 1. [ZM] 


Competency Theme Sample quotes

\section{Encourage Give authority to colleague's work}

empowerment and I've distributed the work. Because I do not have so much energy, and I position myself as the chief designer, I empower the manger of our participation corporation group. [ZS]

Give employees freedom within certain parameters

I still want to weaken my responsibility. My experience in recent years informs me that whenever I weaken myself [my power], they [my employees] all become excellent performers, including my experience in the previous organization, all my employees are better than me [in expertise]. I told them, 'you are an expert in this field, so you are the boss; be courageous with your idea'. After all, they all become experts and I am not. [WT]

Value employee participation

At that time, [our company] was in transition and it is not a stable company, but I needed to give them confidence consistently. But this was invisible and untouchable, so there needed to be a way to provide confidence. I provided all the ideas before, but now $50 \%$ of the ideas are from employees. I let them participate, contribute their ideas for this role, and describe their own roles. In the end, [they] became a team. [ZY]

Support to develop others

Provide training to develop individuals

If human nature needs it, according to my analysis, I told all the colleagues at the management level how to build leadership; I told them what were the needs of human nature and what issues our management system could solve with human nature into consideration. If we got the human nature issues solved and all the problems would be solved. [J]

Support team development

They are all experienced and need to prove their value. I hope to pass over the power to them. This is what I am working on right now. I send them to study and invite teachers to teach them. Company organizes various activities, and I let them be in charge of events and I watch them by their side. I ask them what do you think, instead of commanding them to do the things my way. I ask them to make a plan, and improve it in terms of methods and ideas. Today I was talking [to them] about team management, and told [them] 'you all listened to my orders; but now for the sake of organizational long-term development, we need to have a management team'. [ZY]

Provide suggestion and ideas for others' development

I talked to employees in advance what they should learn from the training. This was not just about knowledge, but also how you marketed yourself and let more of your leaders and colleagues remember you. Only by letting others remember you can you have opportunities. Thus 'you have to demonstrate your value'. I told them in advance at what level the conference was, what they should notice, and what they should do there. I made a request of them in advance. If I did not request anything, they would just go there and listen. They would say it was good. However, I not only expected them to listen, but also to express their opinions and let others know he/she was a person with thoughts. If you did not remind him/her, he or she may not know this. [ZS] 
Perspective taking

Solving conflicts

Express appreciation
Good understanding of others' real situations

Ms. [Name] is a Gemini. If she feels pressure, she will deliver that to us. When she complains to you, she wants us to know her work is not easy. But she is in a very good position, she gets the most share interests and she can work for it like a home. She thinks of me as an incredible resource, because she used to work for a foreign enterprise and earned 2 million the most, but now there is no upper limit here. Why is she not happy with it'? I said no way. 'She wants to spend money to extend the business but also has a concern of not using the money because she is new here and that's why she is complaining'. [CL]

Good understanding of other's expectation and thoughts

If employees only get a big bonus, it does not motivate them too much. If the product is selling out a lot nationally, it will motivate them greatly. So as a leader, when you lead employees to do something and get it done, with everybody benefitting from it, they will support you when you name a second project. [Q]

Recognize multiple conflicts

Based on my understanding, I could not ask the president to tell vice president that I could not take the job. This would lead to their conflict, which did not benefit either side. Besides, company A [a subsidiary of company B] had a manager and he would complain to give the work to company B. Why? Because I was an employee of company A. He had so much energy working in the headquarter and he might do all the work. When he heard this, he felt quite unhappy. He thought that company A was doing this project, thus I should not accept this work. The general office manager was not happy too, because this was supposed to be his work and why a branch manager took it. I was the branch manager and our position level difference was not clear. He was the manager of the mother company while I was a manager of a branch company. We had the competition relationship and so he sensed the potential risk. [LY]

Solve conflicts with in a rational approach

I recruited a new employee as my vice president. But he did not do a good job and some people had opinions towards him. When they brought this up, I told them, 'you have to respect him. If he does not handle this issue appropriately, let's talk it then'. Then I told my vice president that he needed to write a statement and he had to involve in this community first. I communicated with them this way [to solve their conflict]. [GG]

Appreciate the work and contribution of others

I have a good team, and my business can work well. If you do not have one, it is difficult to do business. In 2005 my company was producing winter coater with duck feather, nobody knew how to make the four-layer coat. So I introduced a team from outside. [ZZ]

Appreciate the quality of others

I want to throw him out of the company several times and I think there will be no difference between throwing him out and playing with him. I still appreciate his insistence. I feel I am not anxious when he is here. I can be famous without creating this company, but he cannot. He cannot let it go and he is very determined. I cannot only tell whether he treats me well but also see his qualities. He has good qualities. He is cunning and has lots of issues, but his nature is good and he is a person with love, which I hold dear. [CL] 


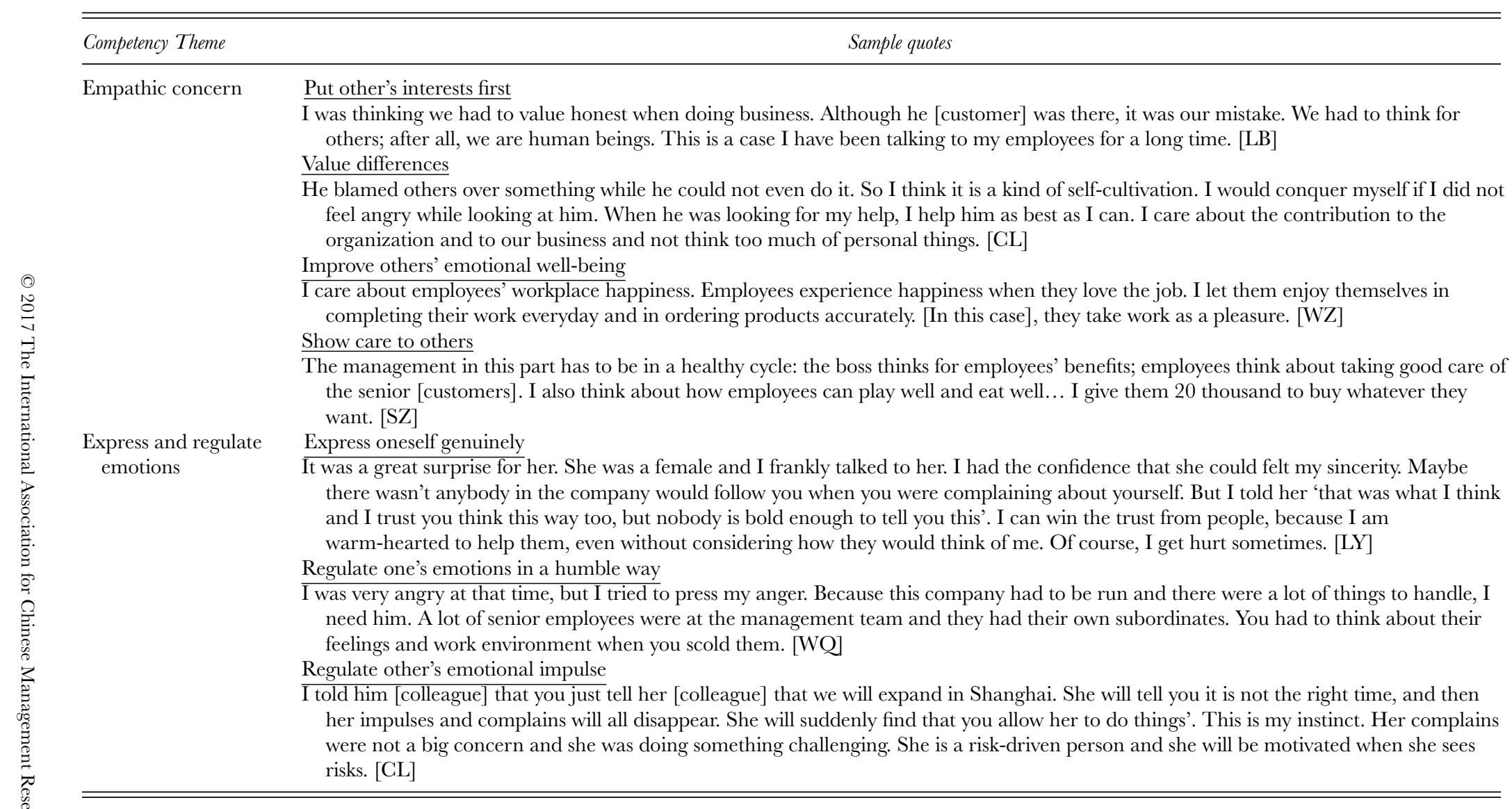




Competency Theme Sample quotes

\section{Affectional bonding Seek emotional support}

Then I told the president of company B and he basically considered from my perspective. My own CEO also told me that he was there to support me even when facing disasters, and he gave me huge support. I think this is what I earn after working so hard for years. On the one side, I was moved; on the other side, I felt I did not do well enough. [LY]

Build an emotional bond with others

Because I have been emphasizing work happily, and I tell my employees that distanced relatives are not as good as close neighbors and colleagues ... distanced relatives cannot help you, neighbors see you once a week, so most of the time you work day and night here and stay together with colleagues at least 7-8 hours per day. [WZ]

Create an environment with affect and consideration

Our every employee has some money for social activities per month and this is a task. For instance, we are in a group and have to spend the money together this month, we can watch movies or have a picnic. This rule is directly linked to money and several thousands are gone every month. So I let everybody to analyze human nature and the emotion bond is built with time. [JJ

Inspiration

Set oneself as a role model

I have to be a role model, which means I have to run to the front line whenever there are difficulties. This does not mean I have to solve a lot of things... but I waste my time with family when the project schedule is busy. I stay with employees and when they see I am there and do not have a weekend, they will continue working without thinking for the weekend. [ZS]

Lead employees with vision

He needs to make a product and work on our platform. I give him the space. He has lot of experience. I told him 'I do not have technology background but I understand customer needs. I just want to create a platform for everybody. You have the power and authority at this platform. At first you need to tell me what you are going to do and what you will demonstrate to customers, then the platform is yours. He is longing for this. [LQ]

Encourage others' confidence and efficacy

Up till now, I have a chance to leave the company and get back to my investment fund. For the current project, I still have to take responsibility, because there is obligation... I have been encouraging my team, 'we must have clear goals and appropriate clear plan, and be consistent. We change wherever is inappropriate'. [MX] 


\section{Outcomes}

Sample quotes

Customer relevant

Customer relationship

Through this business, the customer has been a very reliable customer through all these years. He is not only an honest customer, but also introduces lots of businesses to us. When our employees go to visit other customer, he directs our employees to the right place. [LB]

Customer satisfaction

This morning my client manager told me that he [the client] had calmed down and did not ask any more unreasonable request. Situations like this, I need to give his more comfort and support. [XY]

Employee relevant

Employee performance

They [employees] expect to proceed in their work instead of taking it as a disaster, not like employees in some organizations expecting the weekend all the time and hating the time being so slow. I broke employees' hatred of the work and brought happiness to employees. [JJ]

Employee satisfaction

My coworker acknowledged my capability from the bottom of her heart. Because of my overall management, she was really happy and she was just responsible to take care of her part. She told me, 'this is such a tough thing, and you get it solved. I thought it would be impossible to take it'. [LY]

Employee well-being

Investment to employee safety and health... after that event, I was greatly touched. Now our company is very good at this part. We have employee medical insurance, body injury insurance, safety, health, and high temperature allowance. [LB]

Self relevant

Self well-being

I really like this way of leading and living. With this approach, I continuously decreased my own pressure and felt so relieved on a lot of things. I also learned how to empower to others. [WQ]

Self satisfaction

I felt it was hard to be a new comer because people were not familiar with you and thus might not recognize you. I brought out an idea and said to conduct it this way or that way, which was hard to do. I had to communicate [with others] about it. However, I got this thing done within the time requirement and I felt quite accomplished. [LY]

Organization relevant Positive organizational change

After getting into this business, our company had about 120 employees and we opened five branches over the country. And building on our previous cooperation with business allies, there would be quite a possibility of having continuous projects with them. [CG]

Organizational business

Now the product works very well. We earn about 10 million a year. And this also reflects the efficiency of private enterprises. [LZ] 


\section{NOTES}

The authors thank Senior Editor Bor-Shiuan Cheng and two anonymous reviewers of this manuscript for their valuable suggestions to improve it. We also want to express our deepest gratitude to our colleagues Richard Boyatzis, Melvin Smith, Yunxia Zhu, Leigh Anne Liu, Kwang-Kuo Hwang, and Peter Ping Li for their generous support and valuable comments.

\section{REFERENGES}

Ainsworth, M. S. 1989. Attachments beyond infancy. American Psychologist, 44(4): 709-716.

Avolio, B. J., \& Bass, B. M. 1995. Individual consideration viewed at multiple levels of analysis: A multi-level framework for examining the diffusion of transformational leadership. The Leadership Quarterly, 6(2): 199-218.

Bakan, D. 1966. The duality of human existence: An essay on psychology and religion. Chicago: Rand McNally.

Baron, R. A., \& Markman, G. D. 2003. Beyond social capital: The role of entrepreneurs' social competence in their financial success. Journal of Business Venturing, 18(1): 41-60.

Bass, B. M., Avolio, B. J., \& Atwater, L. 1996. The transformational and transactional leadership of men and women. Applied Psychology, 45(1): 5-34.

Bass, B. M., \& Steidlmeier, P. 1999. Ethics, character, and authentic transformational leadership behavior. The Leadership Quarterly, 10(2): 181-217.

Bellah, R. N., Madsen, R., Sullivan, W. M., Swidler, A., \& Tipton, S. M. 2007. Habits of the heart: Individualism and commitment in American life. Berkeley: University of California Press.

Black, J. S. 1990. Locus of control, social support, stress, and adjustment in international transfers. Asia Pacific Journal of Management, 7(1): 1-29.

Bowlby, J. 1958. The nature of the child's tie to his mother. International Journal of PsychoAnalysis, 39: $350-373$.

Boyatzis, R. E. 2009. Competencies as a behavioral approach to emotional intelligence. Journal of Management Development, 28(9): 749-770.

Boyatzis, R. E., Smith, M. L., \& Blaize, N. 2006. Developing sustainable leaders through coaching and compassion. Academy of Management Learning \& Education, 5(1): 8-24.

Brown, F. W., \& Moshavi, D. 2005. Transformational leadership and emotional intelligence: A potential pathway for an increased understanding of interpersonal influence. Journal of Organizational Behavior, 26(7): 867-871.

Chan, W. T. 1955. The evolution of the Confucian concept Jen. Philosophy East and West, 4(4): 295-319.

Chen, M. J. 2008. Reconceptualizing the competition-cooperation relationship: A transparadoxical perspective. Journal of Management Inquiry, 17(4): 288-304.

Chen, X.-P., \& Chen, C. C. 2004. On the intricacies of the Chinese guanxi A process model of guanxi development. Asia Pacific Journal of Management, 21(3): 305-324.

Cheng, B.-S., Chou, L.-F., Wu, T.-Y., Huang, M.-P., \& Farh, J.-L. 2004. Paternalistic leadership and subordinate responses: Establishing a leadership model in Chinese organizations. Asian Journal of Social Psychology, 7(1): 89-117.

Chua, R. Y., Morris, M. W., \& Ingram, P. 2009. Guanxi vs networking: Distinctive configurations of affect-and cognition-based trust in the networks of Chinese vs American managers. Journal of International Business Studies, 40(3): 490-508.

Chuang, A., Hsu, R. S., Wang, A.-C., \& Judge, T. A. 2015. Does West 'fit' with East? In search of a Chinese model of person-environment fit. Academy of Management Journal, 58(2): 480510 .

Clark, B. H. 2000. Managerial perceptions of marketing performance: Efficiency, adaptability, effectiveness and satisfaction. Journal of Strategic Marketing, 8(1): 3-25.

Conger, J. A., Kanungo, R. N., \& Menon, S. T. 2000. Charismatic leadership and follower effects. Journal of Organizational Behavior, 21(7): 747-767.

Connection, C. C. 1987. Chinese values and the search for culture-free dimensions of culture. Journal of Cross-Cultural Psychology, 18(2): 143-164. 
Cooperrider, D. L., Whitney, D. K., \& Stavros, J. M. 2003. Appreciative inquiry handbook: The first in a series of AI zorkbooks for leaders of change. Bedford Heights, $\mathrm{OH}$ : Lakeshore Communications.

Corbin, J., \& Strauss, A. 2008. Basics of qualitative research: Techniques and procedures for developing grounded theory. Thousand Oaks, CA: Sage Publications.

Crick, N. R., \& Dodge, K. A. 1994. A review and reformulation of social information-processing mechanisms in children's social adjustment. Psychological Bulletin, 115(1): 74.

Davis, M. H. 1983. Measuring individual differences in empathy: Evidence for a multidimensional approach. Journal of Personality and Social Psychology, 44(1): 113-126.

Day, D. V. 2000. Leadership development: A review in context. The Leadership Quarterly, 11(4): 581-613.

De Swert, K. 2012. Calculating inter-coder reliability in media content analysis using Krippendorff's Alpha. Center for Politics and Communication. University of Amsterdam. http://www.polcomm.org/wp-content/uploads/ICR01022012.pdf

Eisenberg, N., \& Fabes, R. A. 1990. Empathy: Conceptualization, measurement, and relation to prosocial behavior. Motivation and Emotion, 14(2): 131-149.

Flanagan, J. G. 1954. The critical incident technique. Psychological Bulletin, 51(4): 327-358.

Galinsky, A. D., Maddux, W. W., Gilin, D., \& White, J. B. 2008. Why it pays to get inside the head of your opponent: The differential effects of perspective taking and empathy in negotiations. Psychological Science, 19(4): 378-384.

Gioia, D. A., Corley, K. G., \& Hamilton, A. L. 2013. Seeking qualitative rigor in inductive research notes on the Gioia methodology. Organizational Research Methods, 16(1): 15-31.

Goleman, D., Boyatzis, R. E., \& MacKee, A. 2002. Primal leadership: Learning to lead reith emotional intelligence. Cambridge, MA: Harvard Business Press.

Grant, A. M., \& Berry, J. W. 2011. The necessity of others is the mother of invention: Intrinsic and prosocial motivations, perspective taking, and creativity. Academy of Management Journal, 54(1): 73-96.

Halberstadt, A. G., Denham, S. A., \& Dunsmore, J. G. 2001. Affective social competence. Social Development, 10(1): 79-119.

Hallgren, K. A. 2012. Computing inter-rater reliability for observational data: An overview and tutorial. Tutorials in Quantitative Methods for Psychology, 8(1): 23-24.

Hartle, F. 1995. Howe to re-engineer your performance management process. London: Kogan Page.

Hayes, A. F., \& Krippendorff, K. 2007. Answering the call for a standard reliability measure for coding data. Communication Methods and Measures, 1(1): 77-89.

Hersey, P., \& Blanchard, K. H. 1969. Management of organizational behavior. Englewood Cliffs, NJ: Prentice-Hall.

Ho, D. Y. 1998. Interpersonal relationships and relationship dominance: An analysis based on methodological relationism. Asian Journal of Social Psychology, 1(1): 1-16.

Hollenbeck, G. P., McCall, M. W., \& Silzer, R. F. 2006. Leadership competency models. The Leadership Quarterly, 17(4): 398-413.

Hopkins, M. M., \& Bilimoria, D. 2008. Social and emotional competencies predicting success for male and female executives.Journal of Management Development, 27(1): 13-35.

Hwang, K. K 2015. Culture-inclusive theories of self and social interaction: The approach of multiple philosophical paradigms. Journal for the Theory of Social Behavior, 45(1): 39-62.

Hwang, K.-K. 2011 . Foundations of Chinese psychology: Confucian social relations. New York: Springer Science \& Business Media.

Hwang, K. K. 1999. Filial piety and loyalty: Two types of social identification in Confucianism. Asian Journal of Social Psychology, 2(1): 163-183.

Ji, L. J. 2008. The leopard cannot change his spots, or can he: Culture and the development of lay theories of change. Personality and Social Psychology Bulletin, 34(5): 613-622.

Jing, R., \& Van de Ven, A. H. 2014. A Yin-Yang model of organizational change: The case of Chengdu bus group. Management and Organization Revieze, 10(1): 29-54.

Johnson, R. E., Selenta, C., \& Lord, R. G. 2006. When organizational justice and the self-concept meet: Consequences for the organization and its members. Organizational Behavior and Human Decision Processes, 99(2): 175-201.

Kark, R., \& Van Dijk, D. 2007. Motivation to lead, motivation to follow: The role of the selfregulatory focus in leadership processes. Academy of Management Revieze, 32(2): 500 528. 
Khanna, T. 2007. Billions of entrepreneurs: How China and India are reshaping their futures and yours. Boston, MA: Harvard Business School Press.

Kirkbride, P. S., Tang, S. F., \& Westwood, R. I. 1991. Chinese conflict preferences and negotiating behaviour: Cultural and psychological influences. Organization Studies, 12(3): 365386.

LaFreniere, P. J., \& Dumas, J. E. 1996. Social competence and behavior evaluation in children ages 3 to 6 years: The short form (SCBE-30). Psychological Assessment, 8(4): 369 377.

Lamm, C., Batson, C. D., \& Decety, J. 2007. The neural substrate of human empathy: Effects of perspective-taking and cognitive appraisal. Journal of Cognitive Neuroscience, 19(1): 4258.

Leung, K. 1988. Some determinants of conflict avoidance. Journal of Cross-Cultural Psychology, 19(1): 125-136.

Li, P. P. 2012. Toward an integrative framework of indigenous research: The geocentric implications of Yin-Yang balance. Asia Pacific Journal of Management, 29(4): 849-872.

Li, P. P. 2008. Toward a geocentric framework of trust: An application to organizational trust. Management and Organization Revieze, 4(3): 413-439.

Li, P. P. 2007a. Guanxi as the Chinese norm for personalized social capital: Toward an integrated duality framework of informal exchange. In H. W. Yeung (Ed.), Handbook of research on Asian business: 62-83. Cheltenham, UK: Edward Elgar.

Li, P. P. 2007b. Towards an interdisciplinary conceptualization of trust: A typological approach. Management and Organization Revieze, 3(3): 421-445.

Markus, H. R., \& Kitayama, S. 1991. Culture and the self: Implications for cognition, emotion, and motivation. Psychological Revieze, 98(2): 224-253.

Maxwell, J. A. 2012. Qualitative research design: An interactive approach. Thousand Oaks, CA: Sage Publications.

Mayer, J. D., DiPaolo, M., \& Salovey, P. 1990. Perceiving affective content in ambiguous visual stimuli: A component of emotional intelligence. Journal of Personality Assessment, 54(34): 772-781.

Mayer, J. D., Salovey, P., \& Caruso, D. R. 2004. Emotional intelligence: Theory, findings, and implications. Psychological Inquiry, 1(3): 197-215.

McAllister, D. J. 1995. Affect- and cognition-based trust as foundations for interpersonal cooperation in organizations. Academy of Management Journal, 38(1): 24-59.

McClelland, D. C. 1973. Testing for competence rather than for 'intelligence'. American Psychologist, 28(1): 1-14.

McClelland, D. C. 1976. A guide to job competency assessment. Boston: McBer.

Mencius \& Lau, D. C. 1995. Mencius says. Singapore: Federal Publications.

Motowidlo, S. J., Carter, G. W., Dunnette, M. D., Tippins, N., Werner, S., Burnett, J. R., \& Vaughan, M. J. 1992. Studies of the structured behavioral interview. Journal of Applied Psychology, 77(5): 571-587.

Pan, Y., Rowney, J. A., \& Peterson, M. F. 2012. The structure of Chinese cultural traditions: An empirical study of business employees in China. Management and Organization Revieze, 8(1): 77-95.

Parker, S. K., \& Axtell, C. M. 2001. Seeing another viewpoint: Antecedents and outcomes of employee perspective taking. Academy of Management Journal, 44(6): 1085-1100.

Patton, M. Q. 1990. Qualitative evaluation and research methods. Thousand Oaks, CA: Sage Publications.

Peelle, H. E. 2006. Appreciative inquiry and creative problem solving in cross-functional teams. The Journal of Applied Behavioral Science, 42(4): 447-467.

Peng, M. W., Lu, Y., Shenkar, O., \& Wang, D. Y. 2001. Treasures in the China house: A review of management and organizational research on Greater China.Journal of Business Research, 52(2): 95-110.

Prahalad, G. K., \& Hamel, G. 1990. The core competence of the corporation. Harvard Business Revieze, 68(3): 79-91.

Pulakos, E. D., Arad, S., Donovan, M. A., \& Plamondon, K. E. 2000. Adaptability in the workplace: Development of a taxonomy of adaptive performance. Journal of Applied Psychology, 85(4): $612-624$.

Reynolds, W. J., \& Scott, B. 1999. Empathy: A crucial component of the helping relationship. Journal of Psychiatric and Mental Health Nursing, 6(5): 363-370. 
Reyt, J. N., \& Wiesenfeld, B. 2015. Seeing the forest for the trees: Exploratory learning, mobile technology, and knowledge workers' role integration behaviors. Academy of Management Journal, 58(3): 739-762.

Richardson, G. E. 2002. The metatheory of resilience and resiliency. Journal of Clinical Psychology, 58(3): 307-321.

Rose-Krasnor, L. 1997. The nature of social competence: A theoretical review. Social Development, 6(1): 111-135.

Saarni, G. 1999. The development of emotional competence. New York: Guilford Press.

Song, F., Cadsby, C. B., \& Bi, Y. 2012. Trust, reciprocity, and guanxi in China: An experimental investigation. Management and Organization Revieze, 8(2): 397-421.

Sparks, P., \& Shepherd, R. 1992. Self-identity and the theory of planned behavior: Assesing the role of identification with 'green consumerism'. Social Psychology Quarterly, 55(4): 388-399.

Stryker, S., \& Burke, P.J. 2000. The past, present, and future of an identity theory. Social Psychology Quarterly, 63(4): 284-297.

Tan, J. 1996. Regulatory environment and strategic orientations in a transitional economy: A study of Chinese private enterprise. Entrepreneurship: Theory and Practice, Fall: $31-44$.

Triandis, H. G., \& Suh, E. M. 2002. Cultural influences on personality. Annual Revieze of Psychology, 53(1): 133-160.

Tsang, E. W. 1998. Inside story: Mind your identity when conducting cross national research. Organization Studies, 19(3): 511-515.

Tu, W. M. 2012. Confucian spirituality in contemporary China. In F. Yang \& J. Tamney (Eds.), Confucianism and spiritual traditions in modern China and beyond: 75-96. Boston: Brill.

Van Dierendonck, D. 2011. Servant leadership: A review and synthesis. Journal of Management, 37(4): 1228-1261.

Van Kleef, G. A., Homan, A. C., Beersma, B., Van Knippenberg, D., Van Knippenberg, B., \& Damen, F. 2009. Searing sentiment or cold calculation? The effects of leader emotional displays on team performance depend on follower epistemic motivation. Academy of Management Journal, 52(3): 562-580.

Wang, J. 2011. Understanding managerial effectiveness: A Chinese perspective. Journal of European Industrial Training, 35(1): 6-23.

Wank, D. L. 1996. The institutional process of market clientelism: Guanxi and private business in a South China city. The China Quarterly, 147: 820-838.

Waters, E., \& Sroufe, L. A. 1983. Social competence as a developmental construct. Developmental Revieze, 3(1): 79-97.

Wei, H., \& Li, S. 2011. Confucian nurturing doctrine of xin (heart-mind) its enlightenment to organization research. Journal of Management Development, 30(7/8): 753-765.

Wong, C. S., \& Law, K. S. 2002. The effects of leader and follower emotional intelligence on performance and attitude: An exploratory study. The Leadership Quarterly, 13(3): 243 274.

Xiao, Z., \& Tsui, A. S. 2007. When brokers may not work: The cultural contingency of social capital in Chinese high-tech firms. Administrative Science Quarterly, 52(1): 1-31.

Xin, K. K., \& Pearce, J. L. 1996. Guanxi: Connections as substitutes for formal institutional support. Academy of Management Journal, 39(6): 1641-1658.

Yeates, K. O., \& Selman, R. L. 1989. Social competence in the schools: Toward an integrative developmental model for intervention. Developmental Revieze, 9(1): 64-100.

Zhang, J.-D., Liu, L. A., \& Liu, W. 2015. Trust and deception in negotiation: Culturally divergent effects. Management and Organization Revieze, 11(01): 123-144.

Zhang, Y., Waldman, D. A., Han, Y. L., \& Li, X. B. 2015. Paradoxical leader behaviors in people management: Antecedents and consequences. Academy of Management Journal, 58(2): $538-566$.

Zhu, Y. 2013. The role of Qing (positive emotions) and Li (rationality) in Chinese entrepreneurial decision making: A Confucian Ren-Yi wisdom perspective. Journal of Business Ethics, 126(4): 613-630. 
Hongguo Wei (hxw243@case.edu) is an assistant professor at the University of Central Oklahoma. She is very passionate about research on emotions (e.g., compassion, empathy, and emotional intelligence), followership and leadership, workplace relationships, and research methods. She is also working on exploring moral emotions as the micro foundation of institutional process.

Diana Bilimoria, PhD (diana.bilimoria@case.edu) is KeyBank Professor and Chair and Professor of Organizational Behavior at the Weatherhead School of Management, Case Western Reserve University. Her research focuses on gender, diversity and inclusion in leadership and governance. She has written several books and has published extensively in leading journals and edited volumes. More detailed information on Dr. Bilimoria is available at: http: //faculty.weatherhead.case.edu/bilimoria.

Shaobing Li (lis18@miamioh.edu) is a doctoral student in Educational Leadership at Miami University. His research interests reside in the intersection of multicultural education, leadership, moral character, institutional research and Chinese philosophy. Prior to joining the doctoral program at Miami University, he received his $\mathrm{PhD}$ degree in Philosophy at Beijing Normal University.

Manuscript received: December 10, 2014

Final version accepted: July 19, 2016 (number of revisions - 2)

Accepted by: Senior Editor Bor-Shiuan Cheng 